\title{
PELA INCORPORAÇÃO DE INFORMAÇÃO FONÉTICA AOS MODELOS FONOLÓGICOS*
}

Adelaide H. P. Silva

\section{Introdução}

$\mathrm{M}$

odelos fonológicos de herança gerativa convencionaram classificar os fatos concernentes aos sons das línguas em dois grandes conjuntos: os universais e aqueles próprios de uma dada língua. Essa diferença, que remonta à Fonologia Gerativa de Chomsky \& Halle (1995[1968]), estabelece um divisor de águas crucial entre os fatos fônicos, no sentido de que se considera que aqueles próprios de uma língua resultam da aplicação de regras fonológicas dessa língua, ordenadas de acordo com exigências do sistema. As regras que engendram tais fatos, portanto, devem ser investigadas e formalizadas por uma análise fonológica. Os fatos universais, ao contrário, não resultam da aplicação de regras fonológicas próprias de um sistema, mas resultam de manobras físicas de implementação. Por isso, são previsíveis e, supostamente, ocorrem em todas as línguas. Logo, não têm de ser contemplados numa análise fonológica.

* Este texto foi apresentado no 5. ${ }^{\circ}$ Encontro do CelSul. Sua autora - docente do Departamento de Lingüística, Letras Clássicas e Vernáculas da UFPR e pesquisadora associada do Laboratório de Fonética e Psicolingüística da Unicamp - agradece as sugestões de um revisor anônimo. 
Um exemplo corrente de fato fônico universal é a duração extrínseca das vogais: elas seriam mais breves diante de obstruintes surdas e mais longas diante de obstruintes sonoras ou soantes (vide Chen, 1970, apud Keating, 1985). No entanto, Keating (op. cit.) observa, através de estudos eletromiográficos, que em línguas como o chinês, o tcheco e o árabe essa relação não se verifica. Ora, não se trata, portanto, de um fato implementacional, previsível. Trata-se, ao contrário, de um fato específico de uma língua e, por isso, é necessário prever regras que gerem vogais mais longas diante de oclusivas surdas e vogais mais breves diante de oclusivas sonoras.

Discutindo esses achados, Keating nota que eles trazem como conseqüência a necessidade de se rever os modelos fonológicos. ${ }^{1}$ Tal revisão implicaria em: a) continuar considerando o módulo fonético constituído de fatos universais, o que levaria à previsão de que quase todos os fatos fônicos deveriam estar contidos no módulo fonológico; ou b) prever que a Fonética contém regras específicas de uma língua, o que significa que uma transcrição fonética não precisaria ser tão estreita; seria necessário, porém, e de alguma maneira, prever quais fatos devem realmente permanecer no componente fonético.

A necessidade de revisão dos modelos fonológicos é reforçada por evidências da literatura fonética acerca das alofonias gradientes: vários estudos ${ }^{2}$ mostram que casos considerados pela literatura fonológica como alofonias envolvendo duas - ou mais - categorias de sons se realizam, na verdade, sobre um contínuo físico, cujas extremidades se constituem de duas categorias. A tendência a uma ou outra extremidade do contínuo tem-se mostrado sensível à estrutura prosódica dos enunciados. Por conseguinte, é preciso prever a representação dessas alofonias na Fonologia de uma língua.

Como fazê-lo, porém, se as alofonias gradientes têm natureza numérica e envolvem $n$ possibilidades entre dois números inteiros, ao passo em que unidades de análise fonológica, como o segmento ou o traço, têm natureza simbólica e permitem apenas a manipulação de oposições?

Observamos que voltar a uma discussão análoga à conduzida por Keating, colocando as alofonias gradientes num domínio fonológico, não resolveria nossa

1 Keating faz menção à Fonologia Gerativa de Chomsky e Halle, que prevê um módulo fonológico, o qual contém informações binárias e escalares da cadeia da fala, sobre as quais se aplicam regras específicas de uma língua. O resultado desse processo é uma representação ou transcrição fonética. Esta, por sua vez, é a entrada de um componente fonético, o qual implementa tal transcrição, juntamente com informações de uma fonética universal, i.e., fatos previsíveis e que, supostamente, ocorrem em todas as línguas.

2 Vide Sproat e Fujimura (1993); Gick (1999), para o inglês; Albano et al. (1998); Albano (2001); Silva (2002) para o português brasileiro. 
questão, pelo motivo exposto acima: a diferente natureza das alofonias e das unidades de análise fonológica.

Browman \& Goldstein $(1986 ; 1989 ; 1990 ; 1992)$ levam a sério essa questão e propõem um modelo que revê radicalmente os modelos de análise fonológica, através de um novo primitivo de análise, única saída aparentemente possível para dar conta dos fatos mencionados. É sobre esse modelo, a Fonologia Articulatória (FAR), e sobre a maneira como ele lida com alofonias contínuas, que se debruça este texto. Passamos, então, a expor os fundamentos da FAR.

\section{Um caso de alofonia não resolvido pela teoria fonológica ${ }^{3}$}

A Fonologia Articulatória, ${ }^{4}$ proposta por Browman \& Goldstein (1986; 1989; 1990; 1992) nasce da observação de que a distância estabelecida entre Fonética e Fonologia deve-se, especialmente, à natureza categórica dos primitivos de análise tomados pela análise fonológica, sejam eles traços ou fonemas; e que unidades dessa natureza ou necessitam de um grande conjunto de regras para dar conta de certos fatos ou simplesmente não conseguem dar conta deles.

Os casos de alofonias das consoantes oclusivas aspiradas e nãoaspiradas em inglês constitui um exemplo contundente para os fatos impossíveis de serem contemplados por modelos fonológicos baseados em unidades da natureza do traço distintivo.

Estudos como o de Kahn (1976, apud Browman; Goldstein, 1992) afirmam a ocorrência de um alofone aspirado, em início de palavra, ou em posição medial, antecedendo vogal acentuada. $\mathrm{O}$ alofone não-aspirado ocorreria nos encontros [s]-oclusiva ou em posição medial na palavra, antecedendo vogais átonas. A ocorrência de um ou outro alofone seria, portanto, previsível, como qualquer outro caso de alofonia fonologicamente condicionada e, portanto, decorreria simplesmente de um mecanismo de implementação. Numa descrição categórica

3 Denominamos teoria fonológica aos modelos que tomam como unidades de análise fonemas, segmentos ou traços distintivos. A esses se contrapõem os modelos dinâmicos de produção de fala, cujo principal expoente é a FAR, a qual será abordada em seguida.

4 É interessante notar que a FAR foi originalmente concebida para ser um modelo passível de implementação num sistema de síntese articulatória elaborado pelos Laboratórios Haskins. Ao modelar a fala para sua implementação em sistema computacional, buscamos compreender seus mecanismos para elaborar um algoritmo eficiente de conversão textofala. 
para esse processo, Kahn atribui um traço [+ spread glottis] para as aspiradas e um traço [- spread glottis] para as consoantes não-aspiradas.

Entretanto, Browman \& Goldstein observam, com base em estudos articulatórios, conduzidos por Cooper (1991, apud Browman; Goldstein, 1992), haver atividade glotal em todos os casos acima mencionados, e não apenas naqueles em que a análise categórica esperaria a realização de uma consoante aspirada. Cooper teria verificado, ainda, a existência de efeito de acento e posição da consoante na palavra sobre a atividade glotal, que seria maior em posição inicial. Na posição medial átona, em contrapartida, a atividade seria menor.

É possível afirmar, então, a existência de um contínuo físico pelo qual se estende a atividade glotal, de modo que quando ela é menor, ela seria percebida como ausência de aspiração e, quando ela é maior, ela seria percebida como aspiração. Sendo esse contínuo condicionado pela posição da oclusiva na palavra e pela posição do acento - uma informação prosódica - é necessário representá-lo na gramática da língua. Voltamos, então, à questão enunciada acima, no final da introdução: como fazê-lo, já que uma análise categórica como a de Kahn dá conta apenas da presença versus ausência de aspiração, e não de sua presença em diferentes graus?

\section{O gesto articulatório: unidade dinâmica}

Para dar conta de um fato gradiente, como a alofonia mencionada acima, é preciso prever um modelo que adote um primitivo de análise distinto daqueles tradicionalmente adotados. Nesse sentido é que Browman \& Goldstein propõem, desde as primeiras versões da FAR, que se tome o gesto articulatório ${ }^{5}$ como unidade de análise.

Inspirados na "Dinâmica de Tarefa", ${ }^{6}$ Browman \& Goldstein propõem que o gesto articulatório é uma unidade que se define a partir de uma equação

5 O termo gesto articulatório não é novo na literatura fonética. No entanto, fora da FAR, ele é concebido simplesmente como um movimento de um articulador. Na FAR, o termo tem outro sentido: é a representação de todas as manobras articulatórias necessárias para se realizar um determinado som da fala.

6 Modelo elaborado por Saltzman; Kelso (1983, apud Browman; Goldstein, 1986), que prevê que um conjunto de articuladores, anatomicamente relacionados, tem uma tarefa a desempenhar como, e.g., um gesto de oclusão labial. 
dinâmica que modela um movimento oscilatório como o descrito por um sistema dinâmico simples, do tipo massa-mola:

$$
\begin{aligned}
& \mathrm{mx} "+\mathrm{bx}{ }^{\prime}+\mathrm{k}\left(\mathrm{x}-\mathrm{x}_{0}\right)=0 \\
& \text { onde, } \mathrm{m}=\text { massa do objeto; } \\
& \mathrm{b}=\text { amortecimento do sistema; } \\
& \mathrm{k}=\text { rigidez da mola; } \\
& \mathrm{x}_{0}=\text { comprimento da mola na posição de repouso; } \\
& \mathrm{x}=\text { deslocamento instantâneo do objeto; } \\
& \mathrm{x}=\text { velocidade instantânea do objeto; } \\
& \mathrm{x} "=\text { aceleração instantânea do objeto. }
\end{aligned}
$$

Alterados os valores relativos à massa do objeto, rigidez da mola e comprimento da mola na posição de repouso, prevê-se a obtenção de diferentes trajetórias do sistema. Também a mudança no movimento inicial da posição instantânea do objeto e na sua aceleração instantânea pode provocar diferenças nas trajetórias. Nesse sentido, mudanças na rigidez da mola introduzem alterações na freqüência de oscilação da massa. Mudanças na posição de repouso da mola ou na sua posição inicial, por sua vez, afetarão a amplitude da oscilação.

Frisamos que as mudanças do parâmetro rigidez da mola $(\mathrm{k})$ e do parâmetro comprimento da mola na posição de repouso $\left(\mathrm{x}_{0}\right)$ trazem uma importante conseqüência teórica ao modelo: é possível prever que os gestos não se apagam como prevêem a Fonologia Autossegmental ou as Geometrias de Traços relativamente aos traços distintivos. Os gestos se sobrepõem uns aos outros, parcial ou totalmente, o que implica, neste último caso, que um gesto pode permanecer escondido entre outros gestos que organizam a cadeia da fala. Essas sobreposições gestuais são implementadas a partir da manipulação dos coeficientes da equação dinâmica - fato que permite considerar a FAR um modelo

7 É preciso ressaltar que transcrevemos aí a equação em sua versão definitiva, tal qual aparece nos textos de Browman e Goldstein, a partir de 1989. No texto de 1986, não há qualquer menção às variáveis amortecimento do sistema e velocidade instantânea do objeto. Não conseguimos recuperar o percurso dos autores, no sentido de inserir essas duas variáveis. Acreditamos, no entanto, que o amortecimento do sistema evite overshoot articulatório, i.e., a variável amortecimento impede que um articulador ultrapasse seu alvo, durante a produção de um gesto articulatório. 
implementacional e, conseqüentemente, a torna distinta de outros modelos fonológicos ditos derivacionais.

Uma outra previsão da FAR é a de que um único gesto pode resultar da ação de dois ou mais articuladores, que se coordenam entre si para cumprir a tarefa especificada pela equação. ${ }^{8}$ Não há, porém, um modo obrigatoriamente imutável pelo qual os articuladores tenham de se coordenar para produzir um gesto; ao contrário, é possível uma flexibilidade articulatória, prevista pela Dinâmica de Tarefa, e especificada por diferentes pesos, característicos dos articuladores. Isso garante que $\mathrm{um} / \mathrm{b} /$, por exemplo, possa ser produzido com mandíbula mais alta diante de /i/ do que de /a/.

A coordenação entre os gestos constitutivos de um segmento - ou de uma seqüência deles - é formalizada em "pautas gestuais". ${ }^{9}$ Nelas, um gesto é representado por pequenas caixas. Variações na sua dimensão vertical têm como conseqüência variações na magnitude dos gestos; variações na sua dimensão horizontal, por sua vez, promovem variações no tempo de ativação do gesto. A magnitude e o tempo de ativação gestuais são diretamente responsáveis pela sobreposição de dois ou mais gestos.

A sobreposição gestual é uma noção de grande importância na FAR, que prevê como conseqüências desse fato: a) efeitos de invariância acústica, como as transições formânticas que emergem, quando um gesto consonantal invariante se sobrepõe a diferentes gestos vocálicos; b) variações alofônicas; c) vários tipos de coarticulação, como as formas variadas do trato, dependentes de contexto. Frisamos que o modelo também prevê que a sobreposição gestual ocorre, necessariamente, entre gestos de camadas diferentes. ${ }^{10}$

Observamos, à guisa de exemplo do formalismo do modelo, a pauta abaixo:

8 A FAR preconiza que a coordenação entre gestos ocorre pela especificação de cada uma das quatro fases de $90^{\circ}$ que constituem cada gesto. Tal coordenação é, concomitantemente, espacial e temporal, já que sua especificação temporal varia em função da freqüência de oscilação, envolvida num dado gesto (ou do parâmetro rigidez na equação dinâmica), e a especificação espacial é intrinsecamente relacionada à mudança de amplitude do gesto (ou do parâmetro posição de repouso, na equação dinâmica).

9 Tradução para gestural score, cf. Albano (2001).

10 Caso dois gestos da mesma camada se sobreponham, afirmam Browman e Goldstein que haverá, como conseqüência, perturbação do movimento das variáveis do trato de cada um desses gestos. Nesse caso, acrescentam, os dois gestos competem entre si, pois tentam realizar tarefas distintas com estruturas articulatórias idênticas. 
FIGURA 1 - EXEMPLO DE PAUTA GESTUAL PARA A PALAVRA [P $\left.{ }^{\mathrm{H}} \mathrm{AM}\right]$, CONFORME SUGESTÃO DE BROWMAN \& GOLDSTEIN (1989, p. 212).

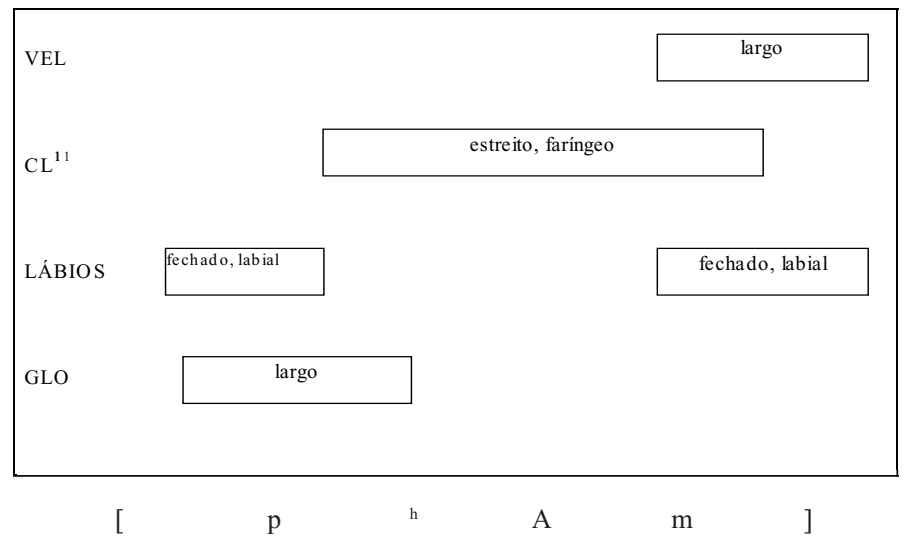

Essa representação pode ser interpretada da seguinte maneira: ao gesto de oclusão bilabial é praticamente concomitante um gesto de afastamento das pregas vocais, o que resulta numa oclusiva surda aspirada $\left[\mathrm{p}^{\mathrm{h}}\right]$. Sincronizado com o término do gesto de oclusão labial há um gesto de corpo de língua, que resulta numa vogal. Observemos que o gesto de afastamento das pregas vocais continua ativo durante o início do gesto de corpo de língua, o que acarreta a presença de aspiração na transição de $\left[\mathrm{p}^{\mathrm{h}}\right]$ para [a] - um efeito coarticulatório, portanto. No final do tempo de realização do gesto de corpo de língua são ativados, concomitantemente, dois outros gestos, o vélico e, novamente, um gesto de oclusão bilabial. A sincronia entre esses dois gestos resulta na produção de uma oclusiva nasal bilabial. Novamente, a pauta gestual retrata a coarticulação entre o gesto da vogal e os gestos da nasal bilabial, ou seja, a produção da nasal começa ainda durante a produção da vogal.

Ainda sobre a pauta gestual acima, é preciso esclarecer que os gestos são especificados para variáveis do trato, que são dimensões de tarefas independentes, as quais especificam o objetivo de um gesto articulatório. $\mathrm{O}$ modelo prevê que cada variável do trato é associada a um conjunto específico de articuladores. Assim:

11 Abreviação para corpo de língua, tradução de tongue blade. 
SILVA, A. H. P. Pela incorporação de informação...

QUADRO 1 - VARIÁVEIS DO TRATO E ARTICULADORES ENVOLVIDOS NA REALIZAÇÃO DA TAREFA ESPECIFICADA PELAS VARIÁVEIS, SEGUNDO BROWMAN \& GOLSTEIN (1992)

\begin{tabular}{|l|l|}
\hline \multicolumn{1}{|c|}{ Variável do trato } & \multicolumn{1}{|c|}{ Articuladores en volvidos } \\
\hline PL - protrusão labial & lábios inferior e superior, mandíbula \\
\hline AL - abertura labial & lábios inferior e superior, mandíbula \\
\hline LCPL - local de constrição da ponta da língua & ponta e corpo da língua, mandíbula \\
\hline GCPL - grau de constrição da ponta da língua & ponta e corpo da língua, mandíbula \\
\hline LCCL - local de constrição do corpo da língua & corpo da língua, mandíbula \\
\hline GCCL - grau de constrição do corpo da língua & corpo da língua, mandíbula \\
\hline VEL - abertura do véu palatino & véu palatino \\
\hline GLO - abertura da glote & glote \\
\hline
\end{tabular}

É preciso ressaltar que o modelo prevê ainda uma variável de raiz de língua, variáveis para controlar a forma das constrições de ponta e corpo de língua e variáveis laríngeas, para controlar pitch, e o movimento vertical da laringe, responsável pela produção de ejetivas e implosivas. Embora previstas, tais variáveis não foram incorporadas à FAR. Na pauta da figura 1, as variáveis do trato são sinalizadas pelas abreviações, em maiúsculas, no canto esquerdo da pauta.

Os gestos que caracterizam cada variável do trato podem, ainda, receber especificação de descritores gestuais para grau e ponto de articulação. Na pauta da figura 1 , os descritores estão dispostos dentro das caixas que representam os gestos articulatórios.

A FAR prevê cinco descritores para grau de constrição: [fechado], [crítico], [estreito], [médio], [largo]. O descritor [fechado] caracteriza oclusivas, ao passo que [crítico] caracteriza fricativas. [estreito], [médio] e [largo], por sua vez, combinados com descritores de local de constrição, caracterizam diferenças entre vogais, sendo a diferença entre os três descritores determinada pelo contraste articulatório e perceptual num sistema vocálico. A diferença entre [largo] e [estreito] pode ser empregada ainda, de acordo com Browman \& Goldstein, para distinguir o tamanho da abertura glotal, relacionada a consoantes aspiradas e não-aspiradas.

No que concerne ao local da constrição, os descritores gestuais são atribuídos aos articuladores lábios, ponta e corpo da língua. Os lábios podem receber especificação [protruso], [labial], [dental]. A ponta da língua, por sua vez, recebe especificação [labial], [dental], [alveolar], [pós-alveolar] ou [palatal]. 
À lâmina, ou corpo, da língua podem ser atribuídos [palatal], [velar], [uvular], [faríngeo]. O modelo prevê que também o articulador raiz da língua pode receber especificação para os mesmos descritores de local de constrição, mas esse dado não é incorporado ao modelo.

Haveria ainda um terceiro descritor gestual, a forma de constrição, responsável, hipoteticamente, pela distinção entre gestos envolvendo os mesmos conjuntos de articuladores e os mesmos descritores de grau e local de constrição. Essa variável não foi incorporada a nenhuma versão do modelo. ${ }^{12}$

Definidos em termos articulatórios, os descritores gestuais são variáveis categóricas do modelo e visam, segundo Browman \& Goldstein, a conferir ao gesto um caráter discreto. ${ }^{13} \mathrm{O}$ caráter dinâmico do gesto lhe é conferido por descritores também dinâmicos, como o parâmetro rigidez, variável em função do grau de constrição, acento e taxa de elocução.

Ainda com relação aos descritores gestuais, é pertinente frisar que assumem na FAR a função que os traços distintivos desempenham nos modelos fonológicos estáticos. De fato, os autores reconhecem que dois gestos são distintos entre si se diferem em, pelo menos, um descritor. A própria notação dos descritores, entre semi-colchetes, lembra a notação dos traços. A diferença é que os descritores não são binários: apenas estão ou não presentes num gesto, i.e., uma vez presentes, podem apresentar comportamento gradiente.

Sem dúvida que a presença da natureza discreta dos descritores gestuais coloca a FAR num paradoxo, pois, embora se pretenda um modelo fonológico distinto dos demais, com um primitivo de natureza dinâmica - portanto distinta da natureza de segmentos ou traços - preserva resquícios de modelos que adoram primitivos de natureza estática.

12 Talvez a incorporação de uma variável dessa natureza, como lateral, possibilitasse um modelamento satisfatório das líquidas na FAR.

13 Quanto à definição articulatória dos descritores gestuais, cabe notar que ela é, muitas vezes, impressionística, conforme crítica de Albano (2001). Os próprios Browman e Goldstein parecem reconhecer isso, mas não vão além de observar que a caracterização dos descritores se inspira em autores como Jespersen (1941, apud Browman; Goldstein, 1989) ou Pike (1943). Além disso, conforme Albano (comunicação pessoal), a estabilização dessas categorias discretas é passível de modelamento na teoria dos sistemas dinâmicos, mas precisa, para tanto, de dados articulatórios colhidos longitudinalmente no período pré-lingüístico, o que, com os recursos tecnológicos disponíveis, é impossível obter. 


\section{O gesto articulatório: unidade discreta}

A seção anterior apresentava o gesto articulatório como uma unidade dinâmica. Tal natureza é conferida ao gesto porque ele se define a partir da especificação: 1) de uma equação dinâmica; 2) do movimento de uma ou mais variáveis, correspondentes à posição instantânea do objeto na equação dinâmica; 3) dos valores dos parâmetros dinâmicos na equação; 4) dos pesos para articuladores individuais.

Ao mesmo tempo em que é um primitivo dinâmico, o gesto também se constitui uma unidade discreta. Para explicar como é conferido ao gesto esse caráter, é preciso tocar, como Browman \& Goldstein (1989), na questão da aquisição da linguagem, i.e., na maneira como emerge o gesto articulatório.

Os autores argumentam que os gestos articulatórios surgem na fala de uma criança, antes do desenvolvimento lingüístico - são unidades prélingüísticas, portanto. Dizem eles que, mesmo no balbucio - fase durante a qual a criança começa a produzir as primeiras sílabas - já é possível identificar os gestos articulatórios. Citando um exemplo de Ferguson \& Farwell (1975, apud Browman; Goldstein, 1989), sobre várias tentativas de uma criança para produzir a palavra inglesa pen, Browman \& Goldstein notam que, embora a criança não produza a palavra em si, os gestos articulatórios presentes nos enunciadostentativa são os mesmos presentes em pen.

Para que a criança produza pen, ou qualquer outra palavra, como na fala adulta, são necessários dois passos, segundo os autores: a) diferenciação e ajuste dos gestos individuais. Ou seja, a partir de um único gesto, mais geral, que serve para produzir tanto oclusivas, como fricativas ou aproximantes, a criança, em fase de aquisição, deve aprender a distingui-los e contrastá-los também no grau de constrição; ${ }^{14}$ b) coordenação dos gestos individuais, pertencentes a uma palavra, quer dizer, não basta que a criança consiga produzir todos os gestos de uma palavra, como no exemplo trazido de Ferguson \& Farwell. É preciso também que a criança os coordene, para produzir a própria palavra.

Notemos que o modelo preconiza que esse aprendizado se dá pela repetição de padrões gestuais. Nesse sentido, essa premissa da FAR vai de encontro à idéia do "aprender fazendo", enunciada independentemente por

14 Frisamos que, para Browman e Goldstein, a aquisição dos gestos articulatórios acompanha a maturação neuromotora da criança. Portanto, essa diferenciação entre gestos e entre aspectos gestuais, como a constrição, é concomitante ao desenvolvimento neuromotor. 
Albano (1990): a criança aprende a realizar as constrições do trato para produzir um determinado gesto, bem como aprende a coordenar esse com outros gestos, para produzir uma palavra, articulando. A Fonologia, por conseguinte, começa a se estabelecer a partir do momento em que a criança se torna capaz de simbolizar, i.e., de associar alguns gestos coordenados a um significado, formando uma palavra. ${ }^{15}$

Em suma: o simbólico (fonológico) emerge a partir da repetição de padrões gradientes, numéricos (fonéticos).

A conseqüência de maior peso dessa relação entre o simbólico e o numérico é que a FAR, ao fim e ao cabo, não necessita de um conjunto de regras derivacionais que façam a tradução de um nível no outro; essa tradução é direta. Percebe-se facilmente, portanto, que um modelo dessa natureza é mais parcimonioso do que outros, que acabam tendo de lançar mão, por vezes, de um conjunto extenso de regras para dar conta de um fato fônico - quando conseguem dar conta do fato. ${ }^{16}$

\section{À guisa de conclusão}

A Fonologia Articulatória, um modelo implementacional cuja análise se constrói a partir da coordenação de unidades definidas pelos parâmetros de uma equação dinâmica, dá um passo bastante ousado com relação aos modelos fonológicos todos: ela revê o primitivo de análise fonológica, definido, no início das investigações em Fonologia, como o fonema ou, mais tarde, como o traço distintivo. Ambas as unidades - ressaltamos - se constroem na base de oposições categóricas.

15 A proposta da FAR é de que o primitivo, tomado para a descrição e análise, organiza a fala infantil e também a adulta. Metodologicamente, esta proposta é vantajosa, pois permite - como afirmam Browman e Goldstein - que a construção da Fonologia seja monitorada acuradamente, pela observação do desenvolvimento das primeiras estruturas gestuais das crianças em direção à estrutura elaborada dos adultos. Essa, aliás, é a perspectiva adotada por Gama-Rossi (1999), em sua tese de doutorado, na qual discute o estabelecimento do ritmo em PB, pela comparação entre a fala infantil e a fala adulta.

16 Vide Silva (2002) para a discussão de um fato fônico do qual modelos fonológicos derivacionais não conseguem dar conta e para o qual a FAR prevê uma representação parcimoniosa. 
Por mais avanços que a teoria fonológica tenha dado desde seu início, prevendo, por exemplo, a organização hierárquica dos traços que constituem a estrutura interna de um dado segmento, o primitivo de análise nunca foi revisto, tendo os modelos mais recentes adotado definições de traços distintivos já encontradas em Chomsky \& Halle, os quais, por sua vez, propõem um inventário de traços distintivos claramente embasados nos traços do modelo estruturalista de Jakobson \& Halle (1956).

Decorre daí um olhar superficial da Fonologia sobre fatos que ela classifica como fonéticos, como as alofonias: as análises fonológicas, no geral, identificam nas línguas, principalmente por análises de outiva, alofonias do tipo variação livre ou fonologicamente condicionadas, as quais podem envolver duas ou mais categorias fônicas. Essas análises, porém, desconhecem os avanços que a Fonética conseguiu, no que concerne à descrição dos dados de fala, graças ao refinamento das técnicas eletrônicas de análise, e que poderiam trazer contribuições significativas, como a observação de que as tais alofonias, em diversos casos, não envolvem duas - ou algumas - categorias, mas um contínuo físico entre elas, o qual, por vezes, mostra-se condicionado pela gramática de uma dada língua. ${ }^{17}$

A Fonologia Articulatória tem o grande mérito de trazer para dentro da lingüística esses fatos através da proposta de uma nova unidade de análise: o gesto articulatório. É mister frisar que a representação das alofonias contínuas na gramática de uma língua só é possível justamente por conta da revisão do primitivo teórico adotado.

Sendo o gesto articulatório uma unidade ao mesmo tempo dinâmica - já que definido pela equação dinâmica que modela o movimento de um sistema oscilatório simples - e simbólica - já que a repetição de um gesto faz com que emerja um padrão gestual - é possível, através dele, fazer uma ponte direta entre o nível fonético e o nível fonológico, sem ser necessário, para isso, prever um conjunto extenso de regras.

Browman \& Goldstein (1992) chegam, inclusive, a propor a inexistência de um módulo fonológico: haveria um único módulo, o fonético, no qual se realizaria toda a tradução do numérico no simbólico. Esta visão é um tanto radical e arriscada, já que confere à Fonética um poder muito grande: esse módulo pode "enxergar" diretamente outros níveis de processamento da linguagem,

17 Para exemplos sobre as alofonias contínuas condicionadas pela gramática de uma dada língua, vide, e.g., Keating (1985); Browman; Goldstein (1992); Sproat; Fujimura (1993); Albano et al.(1998); Albano (2001); Silva (2002). 
como o sintático, sem a necessidade de um módulo que organize a gramática fônica de uma língua.

É por conta dessa previsão arriscada, reforçada por alguns exemplos que evidenciam a necessidade de uma gramática que organize o sistema de sons de uma língua, que Albano (2001) propõe, em sua Fonologia Acústico-Articulatória, um módulo de processamento fônico, no qual se fundem os níveis fonético e fonológico. Os pressupostos da Fonologia Acústico-Articulatória, embora inspirados na FAR, vão além, no sentido de incorporar ao modelo informação de ordem acústica. A discussão deles, contudo, fica para um outro momento, dado que este texto tinha por objetivo principal apresentar a Fonologia Articulatória, na esperança de que mais pesquisadores se interessem por conhecer - e até utilizar-esse modelo.

\section{RESUMO}

A literatura fonética atual tem apresentado exemplos de fatos que, embora usualmente tidos como categóricos são, na verdade, gradientes, i.e., dispõem-se ao longo de um contínuo físico, como é o caso de várias alofonias. Além disso, essas alofonias se mostram sensíveis a fatos gramaticais - como a prosódia - de línguas específicas. Dada a natureza do primitivo de análise adotado pelas teorias fonológicas, elas não conseguem representar os fatos gradientes. A Fonologia Articulatória (Browman; Golstein, 1986; 1989; 1990; 1992), porém, ao propor um novo primitivo de análise - o gesto articulatório, definido em termos dinâmicos por uma equação que descreve um movimento oscilatório simples -, dá conta de representar os fatos gradientes sem precisar recorrer a regras transformacionais, dado que o gesto é também uma unidade abstrata. Este texto, então, expõe os pressupostos desse modelo, buscando observar como se dá essa "tradução" do gradiente no simbólico e buscando apresentar brevemente o modelo, até agora muito pouco conhecido por pesquisadores brasileiros.

Palavras-chave: Fonética, Fonologia, modelos dinâmicos.

\section{ABSTRACT}

Recent phonetic literature argues that some phenomena treated as categorical by traditional phonological literature are gradient indeed. Some allophonies, for example, lay on a physical continuum and, furthermore, are sensitive to grammatical aspects of a given 
SILVA, A. H. P. Pela incorporação de informação...

language, such as its prosodic structure. Due to the categorical nature of the primitives taken by phonological theories, such as the distinctive feature, these theories cannot deal with gradient facts, providing a representation for them. On the other hand, Articulatory Phonology (Browman; Golstein, 1986; 1989; 1990; 1992), proposes a new primitive, the articulatory gesture. This primitive has a dynamical nature, because it is defined in terms of the parameters of an equation that defines a simple oscillatory movement, and it is also abstract, since it represents all the movements of the articulators responsible for the production of a sound. Therefore, the articulatory gesture is capable of "translating" the gradient information into symbolic representation. This text, then, presents Articulatory Phonology, a framework that many Brazilian researchers do not know yet. Key-words: Phonetics, Phonology, dynamic models.

\section{REFERÊNCIAS}

AALBANO, E. C. O gesto e suas bordas: esboço de Fonologia Acústico-Articulatória do português brasileiro. Campinas: Mercado de Letras; ALB; Fapesp, 2001.

et al. A interface fonética-fonologia e a interação prosódia-segmentos. Estudos

Lingüísticos, Campinas, n. 27, 1998. Anais do XLV Seminario do Grupo de Estudos Lingüísticos do Estado de São Paulo - GEL'97, Campinas, 1998. p. 135-143.

BROWMAN, C.; GOLDSTEIN, L. Towards an Articulatory Phonology. Phonology Yearbook, n. 3, p. 219-252, 1986.

. Articulatory gestures as phonological units. Phonology Yearbook, n. 6, p. 201$251,1989$.

. Tiers in Articulatory Phonology. In: KINGSTON, J.; BECKMAN, M. (Eds.). Papers in Laboratory Phonology 1: between the grammar and physics of speech. Cambridge: Cambridge University Press, 1990. p. 341-376.

. Articulatory Phonology: an overview. Phonetica, n. 49, p. 155-180, 1992.

CHOMSKY, N.; HALLE, M. The sound pattern of English. Cambridge: MIT Press, 1995.

GAMA-ROSSI, A. Relações entre o desenvolvimento lingüístico e neuromotor: a aquisição da duração no português brasileiro. Campinas, 1999. Tese (Doutorado) - Lafape/IEL/ Unicamp. 
GICK, B. The articulatory basis of syllable structure: a study of English glides and liquids. Yale, 1999. Tese (Doutorado) - Yale University.

JAKOBSON, R.; HALLE, M. Fundamentals of Language. The Hague: Mouton, 1956.

KEATING, P. Universal phonetics and the organization of grammars. In: FROMKIN, V. (Ed.). Phonetic Linguistics: essays in honor of Peter Ladefoged. New York: Academic Press, 1985. p. 115-132.

PIKE, K. L. Phonemics - a technique for reducing languages to writing. Ann Harbor: University of Michigan Press, 1947.

SILVA, A. H. P. As fronteiras entre Fonética e Fonologia e a alofonia dos róticos iniciais em PB: dados de dois informantes do Sul do país. Campinas, 2002. Tese (Doutorado) Lafape/IEL/Unicamp.

SPROAT, R.; FUJIMURA, O. Allophonic variation in English /1/ and its implications for phonetic implementation. Journal of Phonetics, n. 21, p. 291-311, 1993. 